\title{
Calcium Silicate Cements Application in Lateral Root Perforation Repair: A Case Report with 16-Month Follow-Up
}

\author{
Juan G. Robledo, Pablo A. Rodríguez \\ Endodontics Department, School of Dentistry, University of Buenos Aires, Buenos Aires, Argentina \\ Email: juan.robledo@odontologia.uba.ar, pablorodriguez@dentalmedicine.com.ar
}

How to cite this paper: Robledo, J.G. and Rodríguez, P.A. (2021) Calcium Silicate Cements Application in Lateral Root Perforation Repair: A Case Report with 16-Month Follow-Up. Open Journal of Stomatology, 11, 317-324.

https://doi.org/10.4236/ojst.2021.118028

Received: June 20, 2021

Accepted: August 23, 2021

Published: August 26, 2021

Copyright $\odot 2021$ by author(s) and Scientific Research Publishing Inc. This work is licensed under the Creative Commons Attribution International License (CC BY 4.0).

http://creativecommons.org/licenses/by/4.0/

\begin{abstract}
Lateral root perforations are unfortunate procedures during endodontic treatment and often lead to tooth extraction. Conditioning factors such as time, size, location, inappropriate disinfection and sealing, are indispensable to achieve acceptable long-term outcomes. Calcium silicate cements are bioactive materials used for perforation repair. They can be set in moist environments such as blood, saliva and dentinal fluid making them a reliable material for clinical applications. This case report describes the treatment and repair after a 16-month follow-up of a lateral root perforation of the maxillary lateral incisor.
\end{abstract}

\section{Keywords}

Endodontics, Lateral Root Perforation, Tri/Dicalcium Silicate Cements, Mineral Trioxide Aggregate, Bioactive Materials

\section{Introduction}

According to the American Association of Endodontists (AAE), perforation is defined as "the mechanical or pathologic communication between the root canal system and the external tooth surface" [1].

In the course of endodontic treatment, clinicians confront the need to manage perforations, resulting from operator errors during access preparation, canal negotiation, root canal preparation or internal/external resorption process [2] [3]. If the perforated tooth has strategic value, an indication for repair should be considered [4]. Location of the perforation and time between perforation occurrence and closure, are essential factors for successful repair. Close to the gingival sulcus, the prognosis is uncertain due to contamination with bacteria. If communication is not treated promptly, apical migration of epithelium can occur de- 
veloping a periodontal defect. Large perforations cause more damage in surrounding tissues, making more arduous sealing and repair due to continuous contamination [5] [6].

Tri-Calcium silicate $\left(\mathrm{Ca}_{3} \mathrm{SiO}_{5}\right)$ cements have been utilized as bone cement and recently have been used because of exceptional sealing ability, biocompatibility and bioactivity, as well as regenerative capabilities and antibacterial properties [7] [8] [9]. A material is considered bioactive when induces a positive response from the host. The major source of $\mathrm{Ca}^{2+}$ released comes from the hydration reaction of calcium silicates, and the consequent production of calcium hydroxide [10] [11]. Moisture is necessary for setting reaction and trigger the formation of apatite deposits through bone/osteoblast bioactivity. Apatite deposition can contribute to preserving sealing, through osteoconductivity, osteoinductivity and biocompatibility [12].

This case report describes the treatment and management of lateral root perforation with tri/dicalcium silicate cement and subsequent follow-up after 16 months.

\section{Case Report}

A 55-years-old Hispanic/latino-white male patient was referred to Endodontic Department at University of Buenos Aires 7 days after iatrogenic perforation during endodontic access on maxillary left lateral incisor. The patient's medical history was non-relevant and he rejected any systemic disease and medication allergies. After clinical examination, a temporary restoration was observed and patient accused some discomfort on the attached gingiva. Radiographic examination revealed radiolucency parallel to the long axis compromising the upper third of the tooth (Figure 1).

Local infiltration anesthesia was administered using $4 \%$ carticaine and 1:100.000

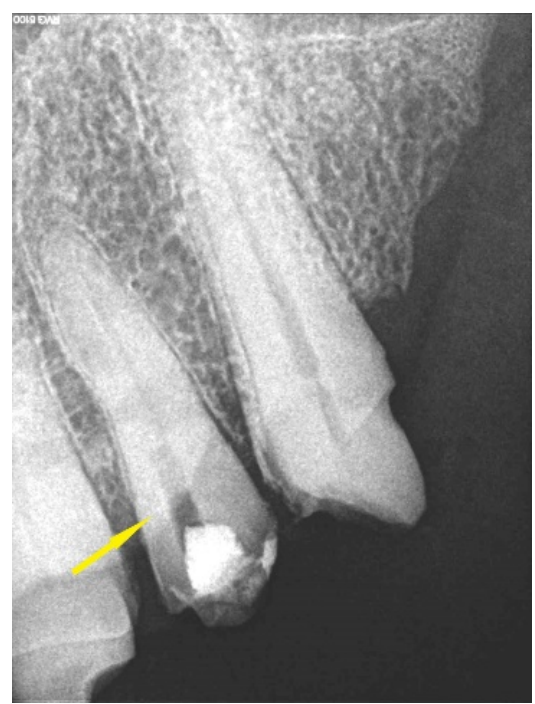

Figure 1. Pre-operative radiograph showing temporary filling over cavity access, perforation size and location parallel to the root canal (yellow arrow), and root canal disposition. 
adrenaline (Anescart Forte, SIDUS, Buenos Aires, Argentina) and then rubber dam isolation was placed. Temporary restoration was removed with high handpiece and round burs, and pulp chamber was irrigated with 5.25\% sodium hypochlorite $(\mathrm{NaOCl})$.

Perforation site was clearly identified under dental microscope $1.0 \times$ magnification (Carl Zeiss, OPMI pico), after drying with paper points mineral trioxide aggregate (EndoSequence BC RRM Fast Set Putty, Brasseler, USA) was placed with Buchanan hand pluggers size 1 and 2 (SybronEndo Corporation, Orange, CA, USA). Working length was estimated in $5-6 \mathrm{~mm}$ controlling hand pressure and thus avoided material extrusion. Immediate restoration was achieved with glass ionomer layer over MTA. Then, orifice canal was located and size 10 stainless steel K-file (Dentsply, Ballaigues, Switzerland) was used to reach the working length estimated in $20 \mathrm{~mm}$, working length radiograph was taken (Figure 2).

Rotary instrumentation was performed with $21 \mathrm{~mm}$ ProTaper Next rotary files (Dentsply Sirona, USA) until .30 tip size/.04 taper. Copious irrigation with 5.25\% sodium hypochlorite $(\mathrm{NaOCl})$ was used intermittently for removing necrotic pulp remnants and dentinal debris. Obturation was achieved using gutta-percha points size 30.04 (Meta Biomed, Chungcheongbuk-do, South Korea) and ADSEAL (Meta Biomed, Chungcheongbuk-do, South Korea) root canal sealer. A sterilized cotton pellet was placed into the pulp chamber with IRM (Dentsply, São Paulo, Brazil) provisional restoration. A post op. radiograph was taken after treatment checking root canal obturation and perforation filling (Figure 3) (Figure 4).

After 16-month follow-up, the patient did not revealed any symptoms with no tenderness to percussion or palpation tests. A digital intraoral periapical radiograph and cone beam computed tomography were taken and showed no periapical radiolucency and continuous PDL. Also, fiber post was observed and perforation filling with MTA (Figure 5) (Figure 6).

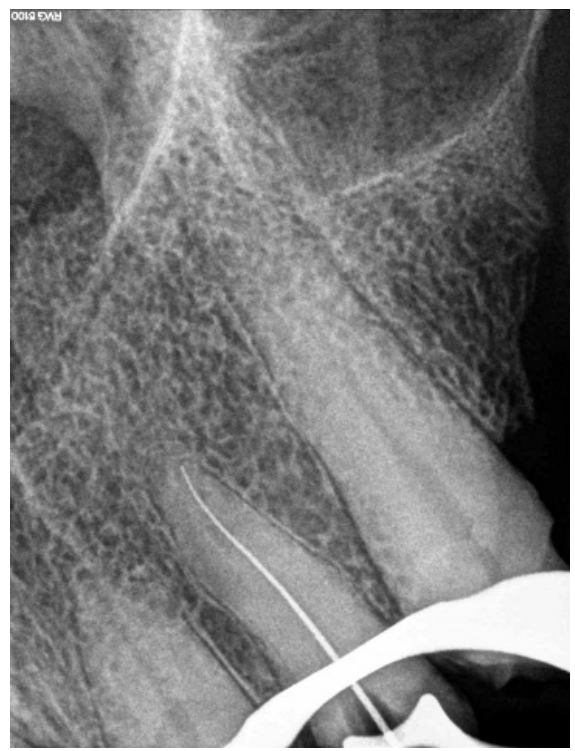

Figure 2. Working length was determined by 15 flex-file at $20 \mathrm{~mm}$. 


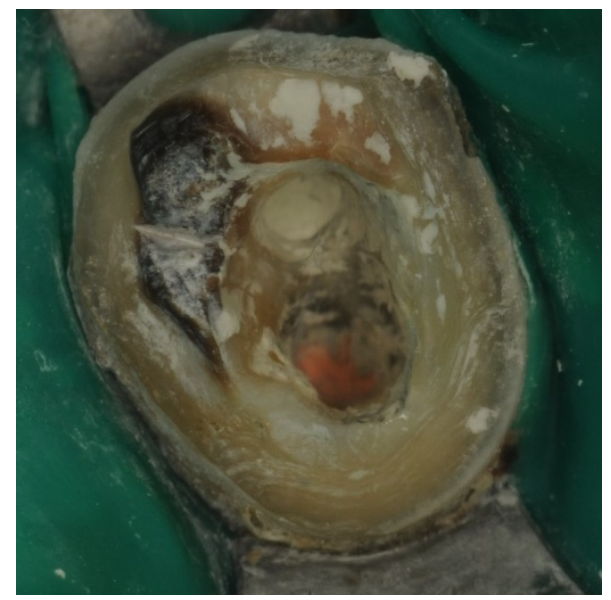

Figure 3. Clinical view showing root canal filling with thermoplasticized gutta-percha and MTA placed on perforation site. MTA filling was covered with a layer of glass ionomer.

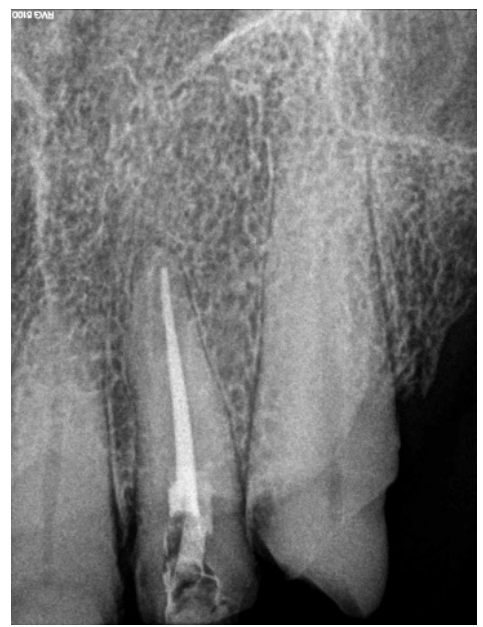

Figure 4. Immediate post-op radiograph. Note root canal obturation with gutta-percha and perforation site filled with MTA.

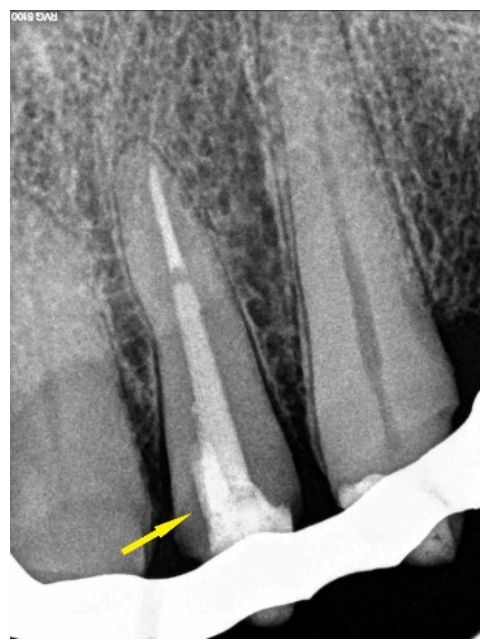

Figure 5. Sixteen months recall examination. Continuous PDL and root canal filling on the apical third can be observed. Fiber post placed in the coronal and medium third of the canal, and perforation site (yellow arrow) filled with MTA. 


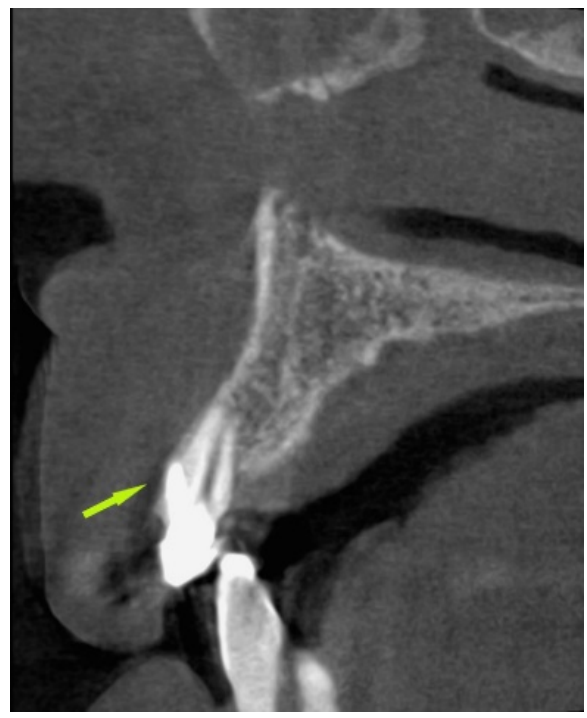

Figure 6. Cone-beam computed tomography (sagittal view) after sixteen months. Perforation repair, size and location (yellow arrow) can be observed. Note the dark space in the root canal (fiber post) and coronal restoration.

\section{Discussion}

The purpose for repairing root perforations is to preserve a healthy periodontium, arresting persistent inflammation and loss of attachment. Perforations close to the crestal bone have the lowest success rate of repair when compared to perforations in other areas of the root [2] [13]. Contamination with bacteria is possible due to the proximity to the gingival sulcus, time between perforation and repair is crucial for predictable results. Immediate sealing of perforation is essential for prevention of infection and prevention of apical migration of the epithelium to the perforation site, avoiding periodontal defect [14] [15].

The patient in this case report was referred 7 days after appointment with his dentist. He presented a large lateral root perforation on the buccal side of the root of maxillary lateral incisor.

Effective sealing ability is essential for perforations management. Mineral Trioxide Aggregate (MTA), has been introduced to seal communications between the tooth and the external surfaces, [16] showing very good outcomes due to hydrophilic characteristics. Currently, is used due to multiple applications in endodontics: antimicrobial activity, root canal sealer, dimensional stability, non-toxic, and promotion of osteogenesis and cementogenesis [17]. However, the adhesive strength between MTA and dentin is still a disadvantage since MTA demand at least 3 - 4 $\mathrm{mm}$ to prevent microleakage. Furthermore, studies have shown that $6 \mathrm{~mm}$ cavities filled with MTA decreased fluid conductance around of $97 \%$ in a fluid filtration technique [18] [19]. In this case report, cavity length was determined at 5 $6 \mathrm{~mm}$.

In moist environments, MTA can release $\mathrm{Ca}^{2+}$ and $\mathrm{OH}^{-}$ions forming apatite. [20] [21]. MTA is a bioactive material that originates calcium hydroxide and stimulate formation of hydroxyapatite structures, [22] creating a hybrid layer be- 
tween dentin and MTA. In this case report, MTA placed in the perforation site was ortho-grade in contact with periodontal tissues. When perforations are of significant size, overfilling to surrounding tissues should be expected.

Mainly composed of dicalcium and tricalcium silicates, inhibits macrophague differentiation into osteoclasts reducing bone resorption, and increase osteoblasts/dental pulp cells proliferation [23] [24]. In contact with blood and interstitial fluids, calcium and phosphate ions in cement and blood respectively, react and precipitate hydroxyapatite or a pseudo-apatite. This bioactivity develops the four phases of wound healing and induces osteogenesis, reconstruction of cementum and reattachment of Sharpey's fibers [25]. Kontakiotis et al. reported that alteration in the $\mathrm{pH}$ of host tissues due to inflammation, could modify the physical and chemical properties influencing the hydration reaction of MTA, at lower ph present in setting process, higher is the porosity [26].

Sealing ability is a key factor for perforation/communication repair, an ideal material should grant a tight seal. Tri/dicalcium silicate cements expand by $0.2 \%$ - $6 \%$, promoting to the sealing capacity. However, they show a certain degree of solubility to enhance the mineralization process in contact with vital tissue during setting time. Materials with high $\mathrm{OH}^{-}$and $\mathrm{Ca}^{2+}$ release are more soluble [27] [28]. In this case report, expansion and setting in moist environment properties of tri/di silicate cements were primary factors for success.

Holland et al. [29] reported that MTA is an effective material repair for root perforations. Studies in dogs' teeth with intentional lateral root perforations repaired with MTA, showed no inflammation and cementum deposition against MTA after 30/180 days due to multiple factors, making it an interesting material for repair. Other authors found clinical success after surgical repair with MTA of a maxillary incisor with lateral perforation at the coronal third and a supracrestal root perforation of a lower left second molar after 15-month follow-up respectively [4] [30].

\section{Conclusion}

When root perforations occur during endodontic treatment, location, size and time of occurrence should be carefully considered. Use of tri/dicalcium silicate materials is recommended due to its ability to create an alkaline environment and releasing calcium ions necessary for precipitation of hydroxyapatite contributing to the healing of surrounding tissues. In this case report, MTA was used to seal the perforation site due to its multiple properties. The repaired tooth was clinically, functionally, and radiographically evaluated. Finally, no symptoms were found after 16-month follow-up. Based on this clinical case report, MTA is suggested as a reliable material for root perforation repair.

\section{Conflicts of Interest}

The authors declare no conflicts of interest regarding the publication of this paper. 


\section{References}

[1] American Association of Endodontists (2016) Glossary of Endodontic Terms. 9th Edition, American Association of Endodontists, Chicago.

[2] Siew, K., Lee, A.H. and Cheung, G.S. (2015) Treatment Outcome of Repaired Root Perforation: A Systematic Review and Meta-Analysis. Journal of Endodontics, 41, 1795-1804.

[3] Martin, L.R., Gilbert, B. and Dickerson, A.W. (1982) Management of Endodontic Perforations. Oral Surgery, Oral Medicine, Oral Pathology, 54, 668-677.

[4] Menezes, R., da Silva Neto, U.X., Carneiro, E., Letra, A., Bramante, C.M. and Bernadinelli, N. (2005) MTA Repair of a Supracrestal Perforation: A Case Report. Journal of Endodontics, 31, 212-214.

[5] Alsulaimani, R.S. (2018) Immediate and Delayed Repair of 2 Sizes of Furcal Perforations in Dogs' Teeth Using Mineral Trioxide Aggregate Cement. Journal of Endodontics, 44, 1000-1006.

[6] Bargholz, C. (2005) Perforation Repair with Mineral Trioxide Aggregate: A Modified Matrix Concept. International Endodontic Journal, 38, 59-69.

[7] Camilleri, J., Sorrentino, F. and Damidot, D. (2013) Investigation of the Hydration and Bioactivity of Radiopacified Tricalcium Silicate Cement, Biodentine and MTA Angelus. Dental Materials, 29, 580-593.

[8] Guo, Y.J., Du, T.F., Li, H.B., Shen, Y., Mobuchon, C., Hieawy, A., Wang, Z.J., Yang, Y., Ma, J. and Haapasalo, M. (2016) Physical Properties and Hydration Behavior of a Fast-Setting Bioceramic Endodontic Material. BMC Oral Health, 16, 1-6.

[9] Clauder, T. and Shin, S.J. (2006) Repair of Perforations with MTA: Clinical Applications and Mechanisms of Action. Endodontic Topics, 1, 32-55. https://doi.org/10.1111/j.1601-1546.2009.00242.x

[10] Han, L. and Okiji, T. (2013) Bioactivity Evaluation of three Calcium Silicate-Based Endodontic Materials. International Endodontic Journal, 46, 808-814.

[11] Dawood, A.E., Parashos, P., Wong, R.H., Reynolds, E.C. and Manton, D.J. (2017) Calcium Silicate-Based Cements: Composition, Properties, and Clinical Applications. Journal of Investigative and Clinical Dentistry, 8, Article ID: e12195.

[12] Gandolfi, M.G., Taddei, P., Tinti, A. and Prati, C. (2010) Apatite-Forming Ability (Bioactivity) of ProRoot MTA. International Endodontic Journal, 43, 917-929. https://doi.org/10.1111/j.1365-2591.2010.01768.x

[13] Asgary, S., Verma, P. and Nosrat, A. (2018) Periodontal Healing Following Non-Surgical Repair of an Old Perforation with Pocket Formation and Oral Communication. Restorative Dentistry \& Endodontics, 43, 2.

[14] Fuss, Z. and Trope, M. (1996) Root Perforations: Classification and Treatment Choices Based on Prognostic Factors. Dental Traumatology, 12, 255-264.

[15] Seltzer, S., Sinai, I. and August, D. (1970) Periodontal Effects of Root Perforations before and during Endodontic Procedures. Journal of Dental Research, 49, 332-339.

[16] Lee, S.J., Monsef, M. and Torabinejad, M. (1993) Sealing Ability of a Mineral Trioxide Aggregate for Repair of Lateral Root Perforations. Journal of Endodontics, 19, 541-544.

[17] Kusai Baroudi, S.S. (2016) Sealing Ability of MTA Used in Perforation Repair of Permanent Teeth: Literature Review. The Open Dentistry Journal, 10, 278-286. https://doi.org/10.2174/1874210601610010278

[18] Lamb, E.L., Loushine, R.J., Weller, R.N., Kimbrough, W.F. and Pashley, D.H. (2003) Effect of Root Resection on the Apical Sealing Ability of Mineral Trioxide Aggre- 
gate. Oral Surgery, Oral Medicine, Oral Pathology, Oral Radiology, and Endodontology, 95, 732-735.

[19] Hirata-Tsuchiya, S., Suzuki, S., Nakamoto, T., Kakimoto, N., Yamada, S. and Shiba, H. (2020) Surgical Sealing of Laterally Localized Accessory Root Canal with Resin Containing S-PRG Filler in Combination with Non-Surgical Endodontic Treatment: A Case Report. Dentistry Journal, 8, 131.

[20] Torabinejad, M. and Parirokh, M. (2010) Mineral Trioxide Aggregate: A Comprehensive Literature Review-Part II: Leakage and Biocompatibility Investigations. Journal of Endodontics, 36, 190-202.

[21] Okiji, T. and Yoshiba, K. (2009) Reparative Dentinogenesis Induced by Mineral Trioxide Aggregate: A Review from the Biological and Physicochemical Points of View. International Journal of Dentistry, 2009, Article ID: 464280.

[22] Camilleri, J., Gandolfi, M.G., Siboni, F. and Prati, C. (2011) Dynamic Sealing Ability of MTA Root Canal Sealer. International Endodontic Journal, 44, 9-20.

[23] Hashiguchi, D., Fukushima, H., Yasuda, H., Masuda, W., Tomikawa, M., Morikawa, K., Maki, K. and Jimi, E. (2011) Mineral Trioxide Aggregate Inhibits Osteoclastic Bone Resorption. Journal of Dental Research, 90, 912-917.

[24] Robledo, J.G. and Rodriguez P.A. (2021) Persistent Apical Periodontitis after Endodontic Treatment: Surgical Management. Global Journal for Research Analysis, 10, 119-121.

https://www.worldwidejournals.com/global-journal-for-research-analysis-GJRA/art icle/persistent-apical-periodontitis-after-endodontic-treatment-surgical-manageme nt/MTkyMDQ=/

[25] Primus, C.M., Tay, F.R. and Niu, L.N. (2019) Bioactive Tri/Dicalcium Silicate Cements for Treatment of Pulpal and Periapical Tissues. Acta Biomaterialia, 96, 35-54.

[26] Agrafioti, A., Tzimpoulas, N., Chatzitheodoridis, E. and Kontakiotis, E.G. (2016) Comparative Evaluation of Sealing Ability and Microstructure of MTA and Biodentine after Exposure to Different Environments. Clinical Oral Investigations, 20, 1535-1540.

[27] Prati, C. and Gandolfi, M.G. (2015) Calcium Silicate Bioactive Cements: Biological Perspectives and Clinical Applications. Dental Materials, 31, 351-370.

[28] Kaup, M., Schäfer, E. and Dammaschke, T. (2015) An In Vitro Study of Different Material Properties of Biodentine Compared to ProRoot MTA. Head \& Face Medicine, 11, 1-8.

[29] Holland, R., Otoboni Filho, J.A., de Souza, V., Nery, M.J., Bernabé, P.F. and Junior, E.D. (2001) Mineral Trioxide Aggregate Repair of Lateral Root Perforations. Journal of Endodontics, 27, 281-284.

[30] Yildirim, G. and Dalci, K. (2006) Treatment of Lateral Root Perforation with Mineral Trioxide Aggregate: A Case Report. Oral Surgery, Oral Medicine, Oral Pathology, Oral Radiology, and Endodontology, 102, e55-e58. 